\title{
Genetic analysis of fiber dimensions and their correlation with stem diameter and solid-wood properties in Norway spruce
}

\author{
Zhi-Qiang Chen ${ }^{1} \cdot$ Bo Karlsson ${ }^{2} \cdot$ Tommy Mörling ${ }^{3} \cdot$ Lars Olsson $^{4}$ • \\ Ewa J. Mellerowicz ${ }^{1}$ Harry X. Wu ${ }^{1,5}$ • Sven-Olof Lundqvist ${ }^{4}$. \\ María Rosario García Gil ${ }^{1}$
}

Received: 19 May 2016/Revised: 13 September 2016 / Accepted: 3 October 2016/Published online: 25 November 2016

(C) The Author(s) 2016. This article is published with open access at Springerlink.com

\begin{abstract}
Adverse genetic correlations between growth traits and solid-wood, as well as fiber traits are a concern in conifer breeding programs. To evaluate the impact of selection for growth and solid-wood properties on fiber dimensions, we investigated the inheritance and efficiency of early selection for different wood-fiber traits and their correlations with stem diameter, wood density, modulus of elasticity (MOE), and microfibril angle (MFA) in Norway spruce (Picea abies L). The study was based on two large open-pollinated progeny trials established in southern Sweden in 1990 with material from 524 families comprising 5618 trees. Two increment cores were sampled from each tree. Radial variations from pith to bark were determined for rings 3-15 with SilviScan for fiber widths in the radial (RFW) and tangential (TFW) direction, fiber wall thickness (FWT), and fiber coarseness (FC). Fiber length (FL) was determined for rings $8-11$. Heritabilities based on rings $8-11$ using joint-site data were moderate to high $(0.24-0.51)$ for all fiber-dimension traits. Heritabilities based on stem cross-sectional averages varied
\end{abstract}

Communicated by R. Burdon

María Rosario García Gil

rosario.garcia@slu.se

1 Umeå Plant Science Centre, Department of Forest Genetics and Plant Physiology, Swedish University of Agricultural Sciences, -901 83 Umeå, SE, Sweden

2 Skogforsk, Ekebo 2250, SE-268 90 Svalöv, Sweden

3 Department of Forest Ecology and Management, Swedish University of Agricultural Sciences, SE-901 83 Umeå, Sweden

4 Wood and Fiber Measurement Laboratory, INNVENTIA, Drottning Kristinas väg 61, SE-114 86 Stockholm, Sweden

5 CSIRO NRCA, Black Mountain Laboratory, ACT, Canberra 2601, Australia from 0.34 to 0.48 and reached a plateau at rings $6-9$. The "age-age" genetic correlations for RFW, TFW, FWT, and FC cross-sectional averages at a particular age with crosssectional averages at ring 15 reached 0.9 at rings $4-7$. Our results indicated a moderate to high positive genetic correlation for density and MOE with FC and FWT, moderate and negative with RFW, and low with TFW and FL. Comparison of several selection scenarios indicated that the highest profitability is reached when diameter and MOE are considered jointly, in which case, the effect on any fiber dimension is negligible. Early selection was highly efficient from ring 5 for RFW and from rings 8-10 for TFW, FWT, and FC.

Keywords Fiber dimensions - Age-age correlations · Heritability · Genetic correlations · Early selection · Picea abies $\cdot$ Norway spruce

\section{Introduction}

In Norway spruce (Picea abies (L.) H. Karst.), stem growth, straightness, and branch angle are commonly assessed as breeding targets based on their economic value (Rosvall et al. 2011). Breeding for growth is a concern, as it could result in adverse effects on solid-wood and fiber dimensions (Rozenberg and Cahalan 1997). For example, negative genetic correlations are commonly observed between annual ring width (as a measure of stem diameter growth) and wood density or modulus of elasticity (MOE) in Norway spruce (Chen et al. 2014; Hannrup et al. 2004; Gräns et al. 2009; Rozenberg and Cahalan 1997) and other conifers (Baltunis et al. 2007; Hong et al. 2014; McLean et al. 2016; Wu et al. 2008).

Genetic correlations of growth and solid-wood traits with fiber dimensions have received less attention, because the determination of fiber dimensions is time- 
consuming and expensive. However, adverse genetic correlations between tree-growth and fiber-dimension traits have been described in various conifer species (Hong et al. 2014; Lenz et al. 2010; Zobel and Jett 1995). Fast-growing trees usually have large radial fiber width (RFW) and tangential fiber width (TFW), as well as low fiber wall thickness (FWT), which are manifested in low wood density (Scallan and Green 1974). For example, Hong et al. (2014) reported a high genetic correlation $(0.77)$ between wood density and FWT and lower $(0.12$ and -0.18 ) for correlations with RFW and TFW, respectively, in a 40-year-old Scots pine (Pinus sylvestris L.) trees. In white spruce (Picea glauca (Moench) Voss), earlywood density was mainly determined by FWT, whereas latewood density was mainly determined by RFW (Lenz et al. 2010).

In Norway spruce, the genetic correlations between growth or solid-wood properties and fiber dimensions have been evaluated using two 19-year-old clonal trials and a 40-year-old full-sib progeny trial (Hannrup et al. 2004). They found that density has generally a significant positive genetic correlation with latewood FWT and a non-significant genetic correlation with earlywood FWT. However, the large variation across trials for wood-quality traits could be attributed to the typical samping error associated with small population size (ca. 200 individuals). Thus, more thorough analyses using more solid-wood and fiber properties are needed using larger datasets involving the processing and product properties of pulp and paper, considering that individual fiber dimensions can have large effects on different properties of pulp and paper (Kibblewhite 1999; Riddell et al. 2005). An example is the relation between fiber width and wall thickness, which refers to how easily they collapse into flat bands that conform to each other and bond to form the paper sheet, influencing many properties, such as sheet density, strength, and surface smoothness (Wimmer et al. 2002).

Another important aspect in conifer breeding is the reduction of the breeding cycle as a means of accelerating the process of tree breeding. To date, most of the studies have focused on early selection for growth and solid-wood quality traits, rather than on fiber properties (Chen et al. 2014; Hong et al. 2015; Kumar and Lee 2002; Li and Wu 2005; Wu et al. 2007). Moreover, research on age-age correlations and early selection efficiency for fiber dimensions has been less extensive, despite the fact that it could provide essential information for designing efficient tree breeding programs for pulp and paper. Existing studies in Norway spruce have reported phenotypic variation for fiber length (FL), RFW, TFW, and FWT from pith to bark (Lundgren 2004; Lundqvist et al. 2002; Lundqvist et al. 2005; Molteberg and Høibø 2007), while age-age correlation and early selection efficiency for fiber dimensions have been estimated only in white spruce (Lenz et al. 2011) and for solid-wood and fiber properties in radiata pine (Pinus radiata D. Don) (Nyakuengama et al. 1997) and Scots pine (Hannrup and Ekberg 1998).

The overall objective of the present study was therefore to explore the effects of selection based on stem diameter and a solid-wood property, MOE, on fiber dimensions in Norway spruce and to investigate the potential for early selection based on RFW, TFW, FWT, fiber coarseness (FC), and FL. Detailed aims of the present study were (1) to quantify inheritance of fiber-dimension traits across annual rings, (2) to explore the genotype-by-environment interactions for fiber-dimension traits, (3) to estimate the genetic correlations of fiberdimension traits, stem diameter, MOE, and microfibril angle (MFA) across annual rings, (4) to estimate age-age correlation and early selection efficiency for fiber-dimension traits, and (5) to evaluate the potential impact of selection based on stem diameter and MOE on fiber dimensions. Our study represents the most extensive genetic study in Norway spruce for fiber dimensions across annual rings.

\section{Materials and methods}

\section{Trial design and measurement}

Two large progeny trials, F1146 (trial 1) and F114 (trial 2) (Chen et al. 2014), were established in 1990, in southern Sweden, with 1373 and 1375 open-pollinated families, respectively. A randomized incomplete block design with single-tree plot was used for both trials. Six healthy trees were sampled for each of 524 families representing 112 provenances. Two cores per tree were sampled at breast height from a total of 5618 trees (2973 and 2645 from trial 1 and trial 2, respectively). Details on characteristics of plant materials, soil type, climate, field design, and sampling method have been reported elsewhere (Chen et al. 2014).

One increment core from each tree was previously used for the determinations and analysis of growth and solidwood traits from pith to bark with the SilviScan instrument at Innventia, Stockholm, Sweden (Chen et al. 2014). The first core was also used for determination of fiberdimension traits. The second core was used for our FL determinations and data analysis, as follows. The SilviScan measurements provided data on variations from pith to bark in wood density, and RFW, TFW, FWT, and FC measured as averages for consecutive $25 \mu \mathrm{m}$ radial intervals, as well as in MFA and MOE for $5 \mathrm{~mm}$ intervals (Evans 1994, 2006; Evans et al. 1995). All rings were identified and their property averages were calculated. Also, property averages for stem cross sections at the ends of each growth season were calculated, through weighting each ring value with the crosssectional area of the ring and assuming that the ring is 
circular around the pith. The data for all samples have been checked for weather-induced false rings to ensure that all rings correspond to one full growth season, so that the ring number equals the cambial age.

In the investigations of age trends and "age-age" correlations (between different ring numbers from the pith), the investigated span was restricted to $3-15$ years, even though ca. $30 \%$ had more rings. These cores originate from fast-grown trees, which reached breast height at a lower age than the rest. Thus, data for ring numbers ("cambial ages") >15 available only for the fastestgrowing trees were excluded. Further, close to the pith, the rings are too curved for accurate measurement based on X-ray transmission and diffraction, and the data quality is not as good as further from the pith. Therefore, also data from rings 1-2 were excluded in the age-age correlation analysis. However, data from all the rings were used when heritabilities, genetic correlations, and genetic gains were estimated for the tree as a unit.

FL was determined from the second core for each of three randomly selected trees per family per site, 3217 trees in total. The wood of the rings 8 to 11 from pith was cut out, macerated, and analyzed with the Kajaani Fiber Lab 3.5 at the Wood Fiber Lab at SLU, Umeå, Sweden, as described elsewhere (Chen et al. 2016). In order to correct for the fiber-cutting unavoidable when sampling by wood increment cores and for sampling error (Bergqvist et al. 1997; Mörling et al. 2003), the measured FL distribution data, including large numbers of cut fibers, was mathematically converted into an estimate of the FL at the wood sampling area within the tree by applying the expectation-maximization algorithm (Chen et al. 2016; Svensson and Sjöstedt-de Luna 2010; Svensson et al. 2006). The approach was recently shown to give more accurate FL estimates than length-weighing or length ${ }^{2}$ weighing algrithms implemented in the Kajaani Fiber Lab 3.5 (Chen et al. 2016).

\section{Statistical analysis}

Variance and covariance components for genetic analyses were estimated using ASReml 3.0 (Gilmour et al. 2009) based on the following linear mixed model for joint-site analysis:

$y_{\mathrm{ijk} k \mathrm{~m}}=\mu+S_{i}+B_{j(i)}+P_{k}+F_{l(k)}+S F_{i l(k)}+e_{\mathrm{ijklm}}$

where $y_{i j k l m}$ is the observation on the $m$ th tree from the $l$ th family within the $k$ th provenance in the $j$ th block within the $i$ th site. $\mu$ is the general mean; $S_{i}$ is the fixed effect of the $i$ th site; $B_{j(i)}$ the fixed effect of the $j$ th block within the $i$ th site; $P_{k}$ is the fixed effect of the $k$ th provenance; $F_{l(k)}$ is the random effect of the $l$ th family within the $k$ th provenance; $S F_{i l(k)}$ is the random interaction effect of the $i$ th site and the $l$ th family within the $k$ th provenance; and $e_{i j k l m}$ is the random residual effect. Based on mixed-model assumptions, the random family-within-provenance effects are $\sim \operatorname{NID}\left(0, \sigma_{\mathrm{f}(\mathrm{p})}^{2}\right)$, the random site-by-family within provenance effects are $\sim \mathrm{NID}(0$, $\left.\sigma_{\text {sf(p) }}^{2}\right)$, while the random residual effects are $\sim \operatorname{NID}\left(0, \sigma_{\mathrm{e}}^{2}\right)$. Preliminary analyses indicated that there was no significant effect for the provenance-by-site interaction for any trait, and consequently, this effect was removed in the final model. The analogous model is applied also for individual rings. Significance of the fixed effects was tested by Wald $F$ test.

Expanding Eq. 1, a bivariate model was constructed to estimate age-age genetic correlations and type-B (betweensites) genetic correlations, and multivariate analysis was used to estimate genetic parameters for different selection scenarios.

Estimates of heritability were obtained for each trait using variance components from the univariate joint-site analysis. Approximate standard errors were calculated using the Taylor series expansion method (Gilmour et al. 2009).

The individual-tree narrow-sense heritability for each trait was estimated by

$$
\hat{h}_{\mathrm{i}}^{2} \approx \frac{4 \hat{\sigma}_{\mathrm{f}(\mathrm{p})}^{2}}{\hat{\sigma}_{\mathrm{f}(\mathrm{p})}^{2}+\hat{\sigma}_{\mathrm{sf}(\mathrm{p})}^{2}+\hat{\sigma}_{\mathrm{e}}^{2}}
$$

where $h_{\mathrm{i}}^{2}$ is the narrow-sense heritability; $\sigma_{\mathrm{f}(\mathrm{p})}^{2}$ is the familywithin-provenance variance; $\sigma_{\mathrm{sf}(\mathrm{p})}^{2}$ is the site-by-familywithin-provenance variance; and $\sigma_{\mathrm{e}}^{2}$ is the residual variance.

\section{Genotype-by-environment interaction}

To evaluate the extent of gentotype-by-environment interaction $(\mathrm{G} \times \mathrm{E})$ for each trait, between-site type-B genetic correlations were used (Burdon 1977), and their approximate standard errors were estimated using the Taylor series expansion method in ASReml (Gilmour et al. 2009). The type-B genetic correlation of additive effects across sites is calculated as

$$
r_{B=} \frac{\operatorname{Cov}_{\left(\mathrm{a}_{1}, \mathrm{a}_{2}\right)}}{\sqrt{\hat{\sigma}_{\mathrm{a}_{1}}^{2} \times \hat{\sigma}_{\mathrm{a}_{2}}^{2}}}
$$

where $\operatorname{Cov}_{\left(a_{1}, a_{2}\right)}$ is the covariance between additive effects of the same traits in different sites and $\sigma_{\mathrm{a}_{1}}^{2}$ and $\sigma_{\mathrm{a}_{2}}^{2}$ are estimated additive variances for the same traits in trial 1 and trial 2, respectively (cf Falconer and Mackay 1996). A one-tailed likelihood ratio test (LRT) against the null hypothesis of genetic correlations of +1 was used to check the significant of $\mathrm{G}$ $\times$ E interaction (Gilmour et al. 2009). 


\section{Phenotypic and genetic correlations}

Phenotypic and genetic correlations (type-A) between traits and age-age genetic correlations for individual traits were estimated as

$$
r_{(x, y)}=\frac{\operatorname{Cov}_{(x, y)}}{\sqrt{\hat{\sigma}_{(x)}^{2} \times \hat{\sigma}_{(y)}^{2}}}
$$

where $\sigma_{(x)}^{2}$ and $\sigma_{(y)}^{2}$ are the estimated phenotypic or genetic variances for traits $x$ and $y$ or the same trait variances at two different ages, respectively, and $\operatorname{Cov}_{(x, y)}$ is the estimated phenotypic or genetic covariance between traits $x$ and $y$ or between early age and reference age. For the sake of comparison, genetic correlations between traits were estimated for the mean values across rings 8-11. Correlations were also recalculated among all traits (except FL) based on crosssectionally-weighted average values from pith to bark.

The efficiency $(E)$ of early selection relative to reference age was calculated as

$\hat{E}_{\text {gen }}=r_{A} \times \frac{i_{E} \times \hat{h}_{E}}{i_{R} \times \hat{h}_{R}}$

where $r_{A}$ is the additive genetic correlation between early and reference ages; $i_{E}$ and $i_{R}$ are the selection intensities at the early age and reference age, respectively; and $h_{E}$ and $h_{R}$ are the square roots of individual-tree narrow-sense heritability estimates at early and reference ages (White et al. 2007). Selection intensities at early age $\left(i_{E}\right)$ and the reference age $\left(i_{R}\right)$ were assumed to be equal.

The correlated response to early selection was calculated as

$C \hat{R}_{y}=i \hat{h}_{x} \hat{h}_{y} r_{A} \hat{\sigma}_{P y}$

where $i$ is the selection intensity (standardized selection differential); $h_{x}$ and $h_{y}$ are the square roots of individual-tree narrow-sense heritabilities for direct-selection $x$ trait and correlated $y$ trait; $r_{A}$ is the estimated additive genetic correlation between traits $x$ and $y$; and $\sigma_{\mathrm{P} y}$ is the phenotypic standard deviation for trait $y$ (Falconer and Mackay 1996).

To study whether there were negative effects on fiber traits when selection was based on diameter or MOE separately or based on selection indices combining growth and stiffness, we constructed selection indices based on single or multiple traits and with or without restriction on fiber traits. A total of six different selection scenarios were considered: (A) Selection based on diameter alone; (B) selection based on MOE alone; (C) selection based on diameter and MOE using an economic weight (increasing $1 \mathrm{GPa}$ in MOE is 10 times as profitable as an increase of $1 \mathrm{~mm}$ in diameter, when average tree height is assumed to be $10 \mathrm{~m}$ and average diameter at breast height is $110 \mathrm{~mm}$ at 21 years of age; Chen et al. 2014). Economic weights for Norway spruce have not been estimated using production-system parameter estimates. Therefore, this index is mainly based on published genetic-parameter estimates for radiata pine (Ivković et al. 2006); (D) selection based on diameter, but with the restriction of no change to FL; (E) selection based on MOE, but with the restriction of no change to FL; and (F) selection based on diameter and MOE using an economic weight, but with the restriction of no change to FL (Mrode and Thompson 2005).

The index coefficients were obtained from

$\mathbf{b}=\mathbf{P}^{-1} \mathbf{G a}$

where $\mathbf{P}$ is the phenotypic variance-covariance matrix for selection traits, $\mathbf{G}$ is the additive genetic variance-covariance matrix between selection traits and objective traits, and $\mathbf{a}$ is the vector of economic weights for each of objective traits (Mrode and Thompson 2005).

For a restricted selection index, Eq. 7 could be modified as

$\mathbf{b}^{*}=\left[\begin{array}{cc}\mathbf{P}^{*} & \mathbf{G}^{*} \\ \mathbf{G}^{*}, & 0\end{array}\right]^{-1}\left[\begin{array}{c}\mathbf{G}^{\mathbf{x}} \\ 0\end{array}\right][\mathbf{v}]$

where $\mathbf{P}^{*}$ is the phenotypic variance-covariance matrix for selection traits, excluding the restricted trait; $\mathbf{G}^{*}$ is the additive genetic variance-covariance matrix between selection traits and traits excluding restricted traits; $\mathbf{G}^{\mathbf{X}}$ is the additive genetic variance-covariance matrix for selection traits excluding restricted traits; $\mathbf{v}$ is the vector of economic weights of all traits; $\mathbf{0}$ is the zero vector (Cunningham et al. 1970). Genetic gain was calculated using mass selection for a single trait. Profitability was calculated using diameter and MOE as

$\operatorname{Pr}=1 G_{d}+10 G_{M}$

where Pr is the profitability; $G_{d}$ is the genetic gain of diameter (mm); and $G_{M}$ is the genetic gain of MOE. The coefficients of 1 and 10 for $G_{d}$ and $G_{M}$ are the economic weights.

\section{Results}

\section{Mean values, coefficients of variation, and heritabilities of fiber dimentions}

All the variables calculated using cross-sectionally weighted averages for rings from pith to bark were larger than those calculated using arithmetic averages from rings 8-11, except for the coefficient of phenotypic variation $\left(\mathrm{CV}_{\mathrm{p}}\right)$ for TFW and heritability for RFW (Table 1). The estimated heritabilities for 
Table 1 Mean values and estimated coefficients of additive $\left(\mathrm{CV}_{\mathrm{a}}\right)$ and phenotypic $\left(\mathrm{CV}_{\mathrm{p}}\right)$ variation and narrow-sense heritabilities $\left(h_{i}^{2}\right)$ for fiberdimension traits using joint-sites data for Norway spruce, based on arithmetic averages for rings 8-11 and cross-sectionally weighted averages for rings from pith to bark

\begin{tabular}{|c|c|c|c|c|c|c|c|c|}
\hline \multirow[b]{2}{*}{ Variables } & \multicolumn{4}{|c|}{ Arithmetic averages for rings $8-11$} & \multicolumn{4}{|c|}{ Cross-sectional averages for rings from pith to bark } \\
\hline & Mean & $\mathrm{CV}_{\mathrm{a}}(\%)$ & $\mathrm{CV}_{\mathrm{p}}(\%)$ & $h_{i}^{2}$ & Mean & $\mathrm{CV}_{a}(\%)$ & $\mathrm{CV}_{\mathrm{p}}(\%)$ & $h_{i}^{2}$ \\
\hline $\mathrm{RFW}(\mu \mathrm{m})$ & 28.91 & 4.01 & 5.61 & $0.51(0.06)$ & 29.43 & 4.07 & 5.90 & $0.48(0.06)$ \\
\hline TFW $(\mu \mathrm{m})$ & 26.40 & 2.57 & 5.20 & $0.24(0.05)$ & 27.45 & 2.87 & 4.95 & $0.34(0.05)$ \\
\hline FWT $(\mu \mathrm{m})$ & 2.14 & 4.82 & 7.62 & $0.40(0.06)$ & 2.15 & 5.54 & 8.29 & $0.45(0.06)$ \\
\hline $\mathrm{FC}(\mu \mathrm{g} / \mathrm{m})$ & 297.5 & 4.64 & 8.56 & $0.29(0.05)$ & 330.60 & 5.15 & 8.88 & $0.34(0.05)$ \\
\hline $\mathrm{FL}(\mathrm{mm})$ & 2.45 & 5.32 & 8.31 & $0.41(0.08)$ & NA & NA & NA & NA \\
\hline
\end{tabular}

Standard errors of heritability estimates are shown in parentheses

$R F W$ radial fiber width, $T F W$ tangential fiber width, $F W T$ fiber wall thickness, $F C$ fiber coarseness, $F L$ mean fiber length, $N A$ not applicable

RFW, TFW, FWT, and FC ranged from 0.34 to 0.48 for crosssectional averages and from 0.24 to 0.51 for arithmetic averages. In both cases, RFW showed the highest heritiability. The estimated heritability for FL was 0.41 . Estimated coeficients of additive genetic variation $\left(\mathrm{CV}_{\mathrm{a}}\right)$ and $\mathrm{CV}_{\mathrm{p}}$ for all the traits were all less than 6 and $9 \%$, respectively.
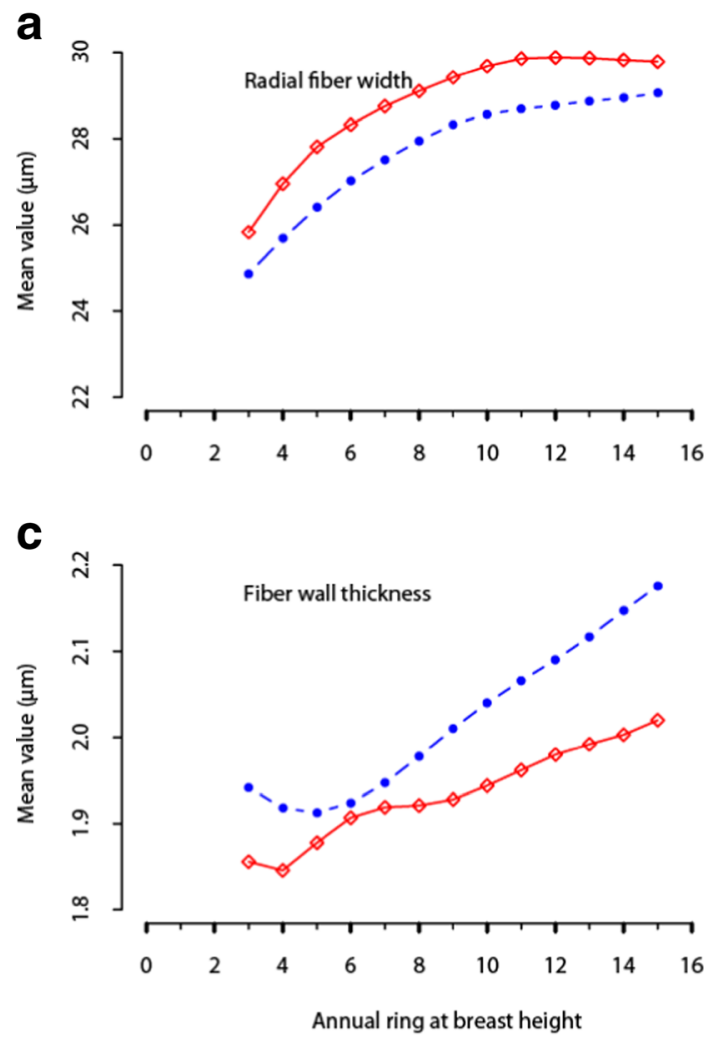

\section{Phenotypic trends among annual rings}

Average of RFW initially increased quickly from ring 3 (ca. $25 \mu \mathrm{m}$ ) to stabilize by ring 10 (ca. $29 \mu \mathrm{m}$ ) (Fig. 1). TFW increased from approximately $25 \mu \mathrm{m}$ in ring 3 to about $27 \mu \mathrm{m}$ in ring 15 and did not stabilize. FWT and FC were all not stabilized
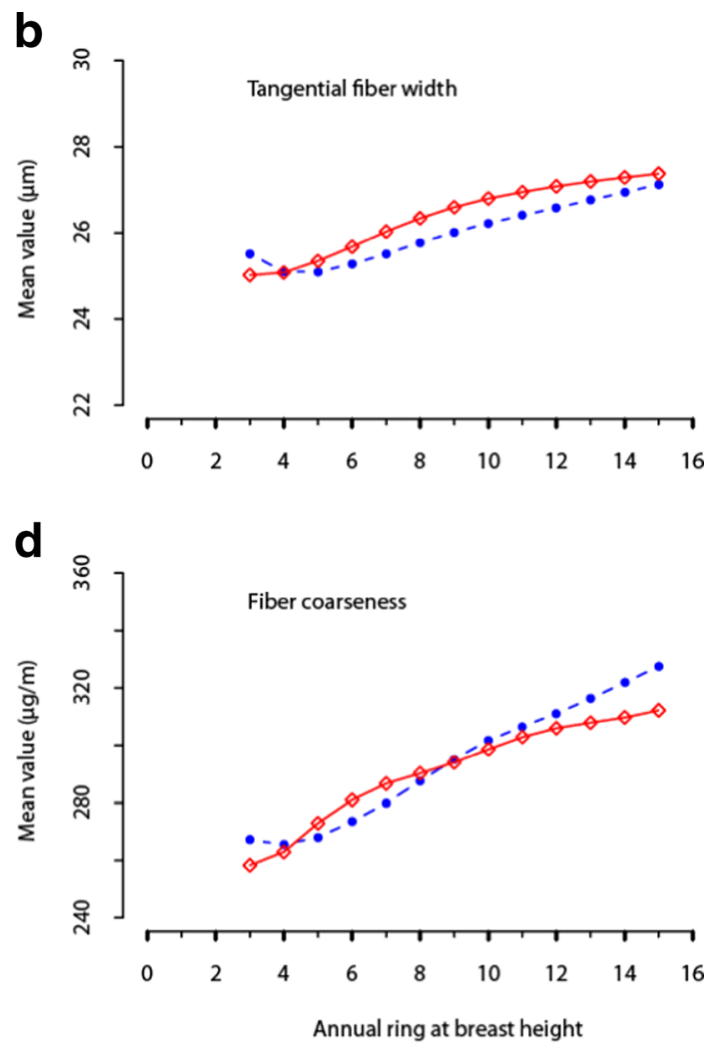

- - S21F9021146 \ S21F9021147

Fig. 1 Pith-to-bark variation in a radial fiber width, $\mathbf{b}$ tangential fiber width, $\mathbf{c}$ fiber wall thickness, and $\mathbf{d}$ fiber coarseness for rings 3 to 15 at breast height for the two trials 
at ring 15. FWT increased from about $1.9 \mu \mathrm{m}$ in ring 3 to about $2.1 \mu \mathrm{m}$ for ring 15. FC showed a similar trend as FWT.

\section{Heritability analysis by ring across sites}

Heritabilities calculated from cross-sectional averages using joint-site data were moderate to high $(\sim 0.3-0.5)$ for all fiberdimension traits for cross-sections from ring 8 outward (Fig. 2). Estimated heritabilities of RFW and FWT increased quickly towards the bark from 0.25 and 0.18 , respectively, at ring 3 , and stabilized from ring 6 at ca. 0.50 and 0.40 , respectively. In contrast, for FC, the heritability increased more gradually and stabilized at about 0.37 from ring 8 . For TFW, the heritability increased gradually from below 0.1 in ring 3 to 0.40 at ring 12 .

\section{Correlations among diameter, solid-wood, and fiber-dimension traits}

Phenotypic and estimated genetic correlations between stem diameter (reflected in ring widths), wood density, MFA, and MOE were previously reported for 5618 trees (Chen et al. 2014). To compare these traits with FL, phenotypic and estimated genetic correlations among fiber-dimension traits based on rings 8-11 for 3217 trees were abstracted and are presented in Table $2 \mathrm{a}$, based on averages for rings $8-11$ only, and in Table $2 \mathrm{~b}$ for cross- sectionally-weighted averages up to ring 15 . Overall, the correlation estimates obtained were quite consistent across both datasets, except for MFA where the genetic correlations were substantially lower when all rings were considered in the analysis. Due to the large dataset in the study, all the estimated standard errors are low, except the correlations between FL and other wood-quality traits.

Type-B genetic correlations between sites for fiberdimension traits were all high $(>0.7)$, indicating low $G \times$ E interaction in the sampled sites (Table 2). Overall, the genetic correlations were higher than the phenotypic correlations, although in general, both correlations were similar regarding both the relative level and the sign of the correlation. Based on rings $8-11$, one exception was the genetic correlation between MFA and RFW that was positive and moderate (0.59), while its equivalent phenotypic correlation was close to zero. Wood density showed moderate and negative genetic correlations with RFW $(-0.51)$ and TFW $(-0.48)$, whereas its correlations were high and positive with FWT (0.93) and FC (0.58). Stem diameter showed a moderate and positive genetic correlation with RFW (0.49) and negative correlation with FWT $(-0.51)$, while the rest of the correlations with the fiber traits were low. High and positive genetic correlations were observed between FWT and FC (0.84) and between FWT and MOE (0.88), while moderate and positive between MFA and RFW (0.59).
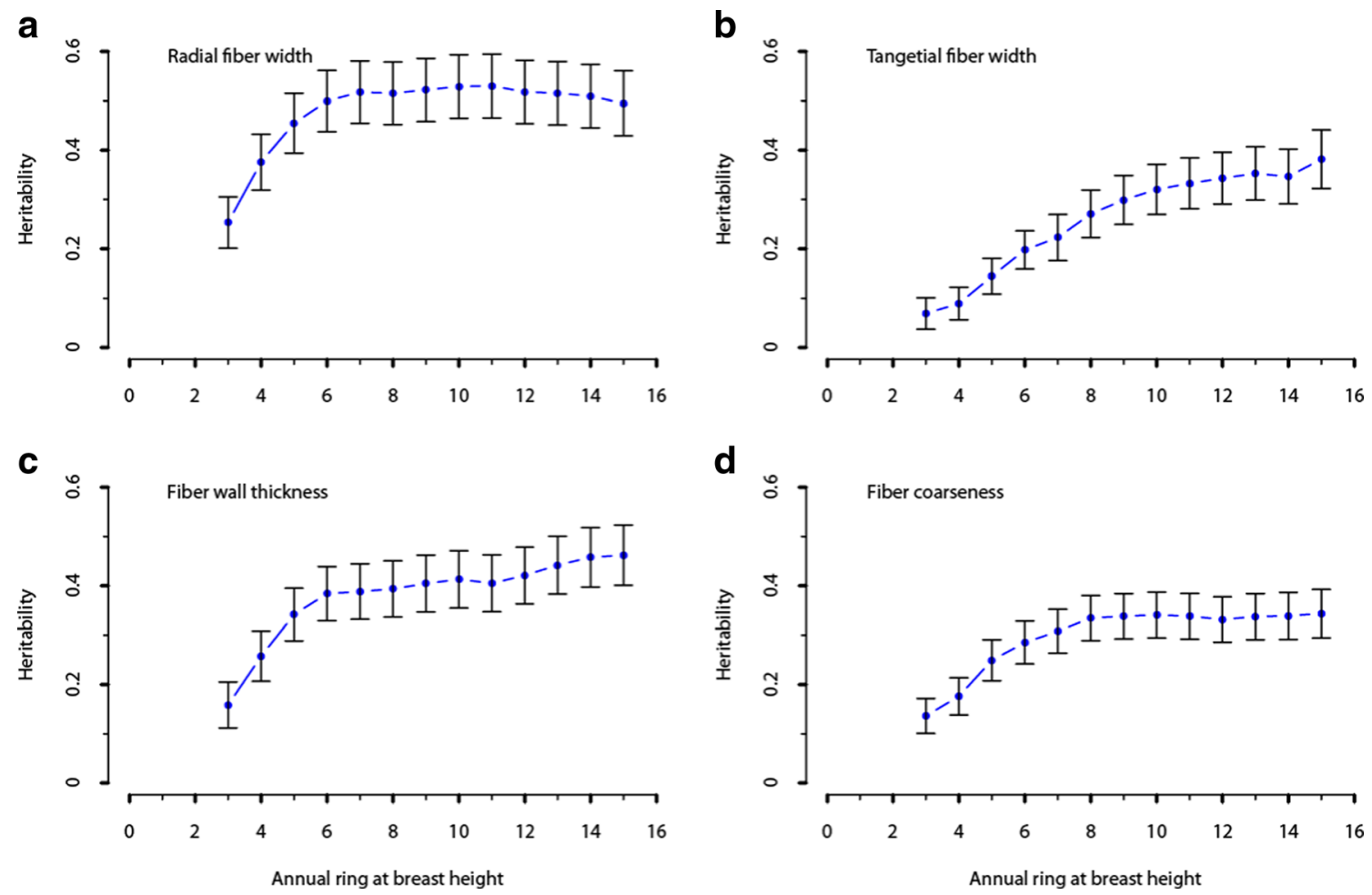

Fig. 2 Estimated heritabilities of cross-sectionally weighted averages for a radial fiber width, $\mathbf{b}$ tangential fiber width, $\mathbf{c}$ fiber wall thickness, and $\mathbf{d}$ fiber coarseness calculated from rings 1 to 15 (pith to bark) at breast height 
Table 2 Estimates of genetic (above the diagonal) and phenotypic correlations (below the diagonal) between Norway spruce wood properties and type-B genetic correlations for different traits between two sites (on the diagonals, in boldface) from the whole increment core measurements in jointsites analysis of trial 1 (F1146) and trial 2 (F1147)

a. Based on arithmetic averages for rings $8-11$

\begin{tabular}{lrllllllrl} 
& \multicolumn{1}{l}{ Diameter } & \multicolumn{1}{l}{ Density } & \multicolumn{1}{l}{ RFW } & \multicolumn{1}{l}{ TFW } & \multicolumn{1}{l}{ FWT } & \multicolumn{1}{l}{ FC } & \multicolumn{1}{l}{ FL } & \multicolumn{1}{l}{ MFA } \\
Diameter & $\mathbf{0 . 6 9 ( 0 . 1 1 )}$ & $-0.61(0.08)$ & $0.49(0.09)$ & $0.21(0.13)$ & $-0.51(0.10)$ & $-0.24(0.13)$ & $-0.11(0.14)$ & $0.81(0.15)$ & $-0.73(0.07)$ \\
Density & $-0.56(0.01)$ & $\mathbf{0 . 7 5 ( 0 . 1 0 )}$ & $-0.51(0.08)$ & $-0.48(0.11)$ & $0.93(0.02)$ & $0.58(0.08)$ & $0.20(0.13)$ & $-0.73(0.15)$ & $0.95(0.04)$ \\
RFW & $0.60(0.01)$ & $-0.57(0.01)$ & $\mathbf{0 . 7 3 ( 0 . 0 9 )}$ & $0.24(0.11)$ & $-0.20(0.11)$ & $0.28(0.11)$ & $0.15(0.13)$ & $0.59(0.16)$ & $-0.59(0.08)$ \\
TFW & $0.24(0.01)$ & $-0.25(0.01)$ & $0.34(0.01)$ & $\mathbf{0 . 7 3 ( 0 . 1 2 )}$ & $-0.25(0.13)$ & $0.15(0.13)$ & $0.23(0.15)$ & $0.06(0.17)$ & $-0.25(0.12)$ \\
FWT & $-0.39(0.01)$ & $0.90(0.00)$ & $-0.25(0.01)$ & $0.09(0.01)$ & $\mathbf{0 . 8 7}(\mathbf{0 . 1 3})$ & $0.84(0.04)$ & $0.34(0.13)$ & $-0.66(0.15)$ & $0.88(0.05)$ \\
FC & $-0.05(0.01)$ & $0.52(0.01)$ & $0.25(0.01)$ & $0.50(0.01)$ & $0.83(0.00)$ & $\mathbf{0 . 9 0}(\mathbf{0 . 1 5})$ & $0.48(0.12)$ & $-0.36(0.16)$ & $0.54(0.10)$ \\
FL & $-0.23(0.02)$ & $0.14(0.02)$ & $0.08(0.02)$ & $0.20(0.02)$ & $0.25(0.02)$ & $0.30(0.02)$ & $\mathbf{0 . 8 4}(\mathbf{0 . 2 1})$ & $-0.19(0.17)$ & $0.21(0.12)$ \\
MFA & $0.32(0.01)$ & $-0.19(0.01)$ & $0.08(0.01)$ & $0.06(0.01)$ & $-0.18(0.01)$ & $-0.10(0.01)$ & $-0.39(0.02)$ & $\mathbf{0 . 7 6 ( 0 . 2 3 )}$ & $-0.90(0.05)$ \\
MOE & $-0.55(0.01)$ & $0.63(0.01)$ & $-0.35(0.01)$ & $-0.22(0.01)$ & $0.56(0.01)$ & $0.29(0.01)$ & $0.37(0.02)$ & $-0.84(0.00)$ & $\mathbf{0 . 9 2}(\mathbf{0 . 1 2})$
\end{tabular}

b. Based on cross-sectional averages for rings from pith to bark, except FL

\begin{tabular}{|c|c|c|c|c|c|c|c|c|c|}
\hline & Diameter & Density & RFW & TFW & FWT & $\mathrm{FC}$ & FL & MFA & MOE \\
\hline Diameter & $0.45^{a}(0.12)$ & $-0.61^{\mathrm{a}}(0.09)$ & $0.51(0.10)$ & $0.31(0.14)$ & $-0.48(0.11)$ & $-0.19(0.15)$ & $-0.15(0.15)$ & $0.54^{\mathrm{a}}(0.17)$ & $-0.75^{\mathrm{a}}(0.09)$ \\
\hline Density & $-0.58^{\mathrm{a}}(0.01)$ & $0.74^{a}(0.08)$ & $-0.51(0.07)$ & $-0.39(0.10)$ & $0.93(0.02)$ & $0.61(0.07)$ & $0.12(0.12)$ & $-0.38^{\mathrm{a}}(0.12)$ & $0.87^{\mathrm{a}}(0.04)$ \\
\hline RFW & $0.64(0.01)$ & $-0.57(0.01)$ & $0.74(0.07)$ & $0.19(0.10)$ & $-0.22(0.09)$ & $0.26(0.10)$ & $0.10(0.12)$ & $0.40(0.13)$ & $-0.58(0.08)$ \\
\hline TFW & $0.31(0.01)$ & $-0.28(0.01)$ & $0.38(0.01)$ & $0.88(0.13)$ & $-0.18(0.11)$ & $0.17(0.11)$ & $0.11(0.13)$ & $-0.01(0.15)$ & $-0.27(0.11)$ \\
\hline FWT & $-0.38(0.01)$ & $0.90(0.00)$ & $-0.22(0.01)$ & $0.08(0.01)$ & $0.84(0.09)$ & $0.85(0.03)$ & $0.22(0.12)$ & $-0.32(0.12)$ & $0.79(0.05)$ \\
\hline $\mathrm{FC}$ & $0.00(0.01)$ & $0.49(0.01)$ & $0.29(0.01)$ & $0.51(0.01)$ & $0.83(0.00)$ & $0.96(0.13)$ & $0.29(0.12)$ & $-0.15(0.13)$ & $0.48(0.10)$ \\
\hline FL & $-0.20(0.02)$ & $0.09(0.02)$ & $0.04(0.02)$ & $0.16(0.02)$ & $0.18(0.02)$ & $0.22(0.02)$ & $\mathbf{0 . 8 4}(0.21)$ & $-0.27(0.17)$ & $0.21(0.12)$ \\
\hline MFA & $0.23^{\mathrm{a}}(0.01)$ & $-0.15^{\mathrm{a}}(0.01)$ & $0.05(0.01)$ & $-0.01(0.01)$ & $-0.16(0.01)$ & $-0.11(0.01)$ & $-0.37(0.02)$ & $0.85^{\mathrm{a}}(0.20)$ & $-0.76^{\mathrm{a}}(0.05)$ \\
\hline MOE & $-0.51^{\mathrm{a}}(0.01)$ & $0.62^{\mathrm{a}}(0.01)$ & $-0.35(0.01)$ & $-0.18(0.01)$ & $0.55(0.01)$ & $0.29(0.01)$ & $0.36(0.02)$ & $-0.83^{\mathrm{a}}(0.00)$ & $0.93^{\mathrm{a}}(0.12)$ \\
\hline
\end{tabular}

Upper part (a) is based on arithmetic averages for rings 8-11; lower part (b) is based on cross-sectional averages for rings from pith to bark. Approximate standard errors are shown in parentheses. The significant $\mathrm{G} \times \mathrm{E}$ interactions in type-B genetic correlations were marked by bold fonts and italics $R F W$ radial fiber width, $T F W$ tangential fiber width, $F W T$ fiber wall thickness, $F C$ fiber coarseness, $F L$ fiber length

${ }^{\mathrm{a}}$ The results were reported in the paper (Chen et al. 2014)

RFW and TFW showed low to absent correlations with FL, 0.15 and 0.23 , respectively. Genetic correlation of FL with MOE was low (0.21).

Observed genetic correlations were consistent across individual annual rings (Table 3) (only those correlations of interest are showed). For example, correlations between density and $\mathrm{FC}$ varied from 0.47 to 0.70 ; correlations between FWT and $\mathrm{FC}$ varied from 0.81 to 0.91 ; and correlations between RFW and TFW varied from 0.11 to 0.32 .

It is important to realize that there are strict relationships between some of the traits investigated, due to their nature and to the way they have been characterized. The local wood density may be calculated as the local FC (fiber mass/length unit) times the number of fibers per area unit, which in turn is mathematically related to RFW and TFW. And as the relative variations in the ring averages of RFW and TFW are limited, those of density and FC will show very strong correlation. Further, local FWT may be calculated from the local density, RFW, and TFW, as well as the density of the fiber wall. And as the variation in this latter density is so small, it is postulated as constant and the equation is used in the measurements to calculate the FWT.
Further, MOE has a strong positive correlation with wood density, which is exploited by using density in the estimation of MOE. So, high phenotypic correlations among these parameters should be expected, as they largely reflect physical relationships.

\section{Age-age correlation and early expected selection efficiency}

Based on the reference ring 15 , the age-age genetic correlations reached 0.9 at rings $4,6,6$, and 7 for RFW, TFW, FWT, and FC, respectively (Fig. 3). Early selection efficiency for RFW increased quickly from about 0.6 at ring 3, stabilizing at ca. 1 after ring 6 . For FC, selection efficiency increased more progressively and stabilized at ca. 1 after ring 8 . For TFW and FWT, selection efficiency also increased more progressively, reaching values of 0.9 at rings 10 and 8 , respectively, and continued to increase toward the reference ring 15 .

\section{Response for different selection scenarios}

The results of six selection scenarios are shown in Table 4 with the same selection intensity $(i)$ of 2.67 (i.e., $1 \%$ ). 
Table 3 Estimated genetic correlations among diameter, density, RFW, TFW, FWT, and $\mathrm{FC}$ for each ring number (from 3 to 15 ) in Norway spruce from combined analyses of the two trials

\begin{tabular}{lllllll}
\hline $\begin{array}{l}\text { Ring } \\
\text { cambial age }\end{array}$ & $\begin{array}{l}\text { Diameter and } \\
\text { RFW }\end{array}$ & $\begin{array}{l}\text { Density and } \\
\text { RFW }\end{array}$ & $\begin{array}{l}\text { Density and } \\
\text { FWT }\end{array}$ & $\begin{array}{l}\text { Density } \\
\text { and FC }\end{array}$ & $\begin{array}{l}\text { FWT and } \\
\text { FC }\end{array}$ & $\begin{array}{l}\text { RFW and } \\
\text { TFW }\end{array}$ \\
\hline 3 & $0.19(0.27)$ & $-0.39(0.15)$ & $0.93(0.03)$ & $0.57(0.15)$ & $0.84(0.07)$ & $0.22(0.23)$ \\
4 & $0.45(0.12)$ & $-0.60(0.08)$ & $0.95(0.02)$ & $0.59(0.12)$ & $0.82(0.06)$ & $0.16(0.17)$ \\
5 & $0.55(0.12)$ & $-0.56(0.08)$ & $0.94(0.02)$ & $0.55(0.10)$ & $0.81(0.05)$ & $0.29(0.12)$ \\
6 & $0.70(0.13)$ & $-0.62(0.07)$ & $0.95(0.02)$ & $0.59(0.09)$ & $0.81(0.05)$ & $0.28(0.12)$ \\
7 & $0.51(0.12)$ & $-0.51(0.08)$ & $0.92(0.02)$ & $0.53(0.10)$ & $0.81(0.05)$ & $0.24(0.13)$ \\
8 & $0.36(0.13)$ & $-0.43(0.10)$ & $0.91(0.02)$ & $0.52(0.10)$ & $0.82(0.04)$ & $0.32(0.11)$ \\
9 & $0.48(0.10)$ & $-0.51(0.08)$ & $0.94(0.02)$ & $0.61(0.09)$ & $0.84(0.04)$ & $0.21(0.12)$ \\
10 & $0.60(0.08)$ & $-0.58(0.07)$ & $0.94(0.02)$ & $0.56(0.09)$ & $0.83(0.04)$ & $0.22(0.12)$ \\
11 & $0.55(0.10)$ & $-0.48(0.10)$ & $0.92(0.03)$ & $0.47(0.12)$ & $0.81(0.05)$ & $0.19(0.13)$ \\
12 & $0.50(0.12)$ & $-0.54(0.10)$ & $0.95(0.02)$ & $0.58(0.09)$ & $0.82(0.04)$ & $0.22(0.13)$ \\
13 & $0.55(0.12)$ & $-0.56(0.10)$ & $0.92(0.03)$ & $0.63(0.09)$ & $0.86(0.05)$ & $0.13(0.14)$ \\
14 & $0.61(0.11)$ & $-0.58(0.11)$ & $0.96(0.02)$ & $0.65(0.10)$ & $0.87(0.05)$ & $0.11(0.19)$ \\
15 & $0.20(0.26)$ & $-0.61(0.11)$ & $0.96(0.03)$ & $0.70(0.15)$ & $0.88(0.07)$ & $0.15(0.19)$ \\
\hline
\end{tabular}

Approximate standard errors are shown in parentheses
Selection for increase in diameter alone (scenario A) has a large decrease of MOE $(9.59 \%)$ and incurs a slight decrease of FWT $(-2.93 \%)$ and a slight increase in RFW (3.25\%),
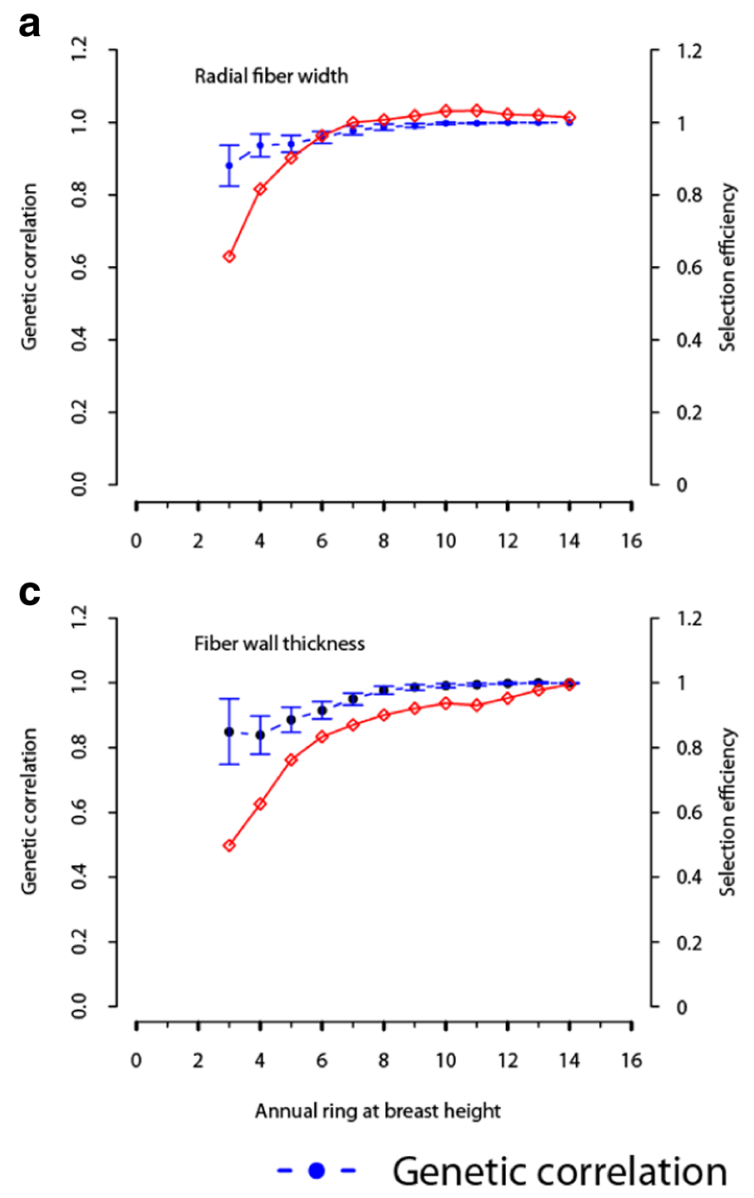

Fig. 3 Estimated age-age genetic correlations (blue) between earlier rings and ring 15 based on the cross-sectional averages for a radial fiber width, b tangential fiber width, $\mathbf{c}$ fiber wall thickness, and d while the effect on the rest of the fiber traits is negligible. Similarly, selection for increase of MOE alone (scenario B) affected FWT $(6.56 \%)$ and RFW (-3.64 \%). FC also
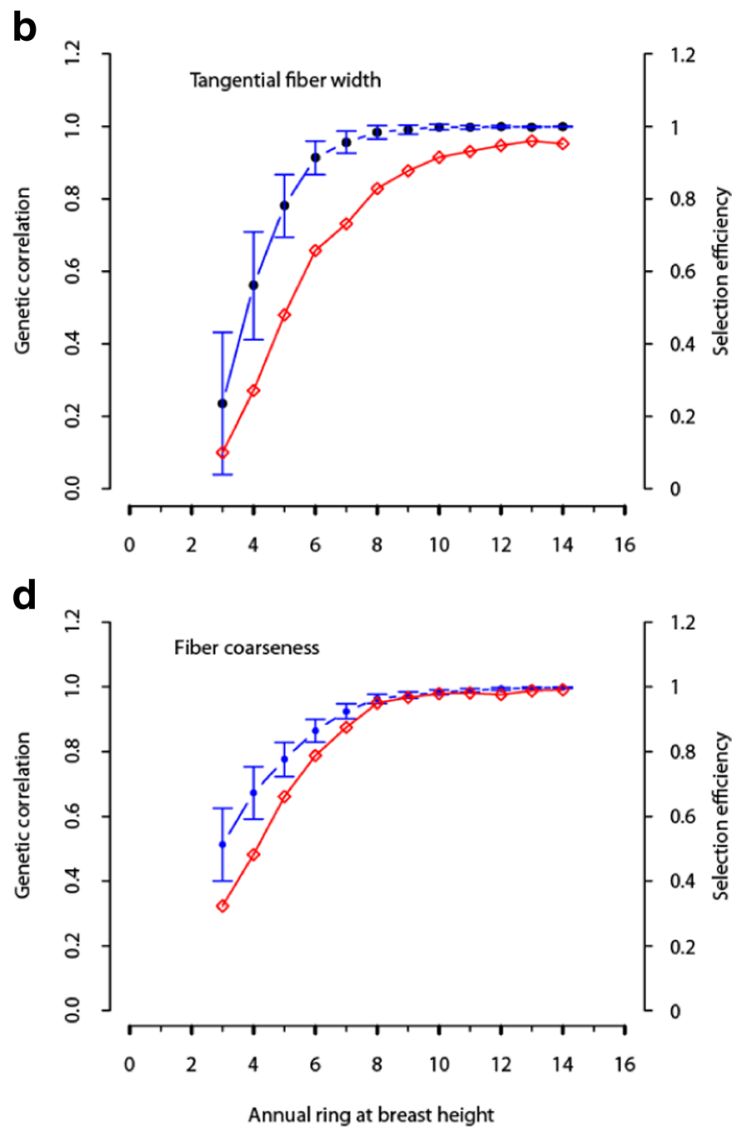

\section{$\diamond \quad$ Selection efficiency}

fiber coarseness, as well as early selection efficiency (red) according to ring number 
increased slightly under scenario B (3.29\%), while diameter was substantially decreased (13.81\%). A selection index for diameter and MOE simultaneously (scenario $\mathrm{C}$ ) resulted in a lesser increase in diameter $(10.53 \%)$ compared with scenario $\mathrm{A}$, but the negative impact on MOE is averted $(0.16 \%)$. Scenario C affected only FC (3.08 \%). Selection for diameter with restriction of no change to FL (scenario D) and for MOE with restriction of no change to FL (scenario E) had a similar outcome as scenarios A and B, respectively. Selection based on joint diameter and MOE traits with restriction of no change to FL (scenario F) had a similar increase in diameter and decrease in MOE as scenario $\mathrm{C}$, but a lower effect on FC. Profitability is higher for a scenario where both diameter and MOE are considered jointly, while adding FL to the equation has no significant effect.

\section{Discussion}

\section{Trait phenotypic variation and heritability for fiber-dimension traits across rings}

In this study, TFW, FWT, and FC increase gradually from pith to bark. These results are also in agreement with the results reported by Lenz et al. (2010) for white spruce and by Mitchell and Denne (1997) for Sitka spruce (Picea sitchensis (Bong.) Carrière). Lundgren (2004) found that TFW, FWT, and $\mathrm{FC}$ have low and stable values for the first few rings close the pith and a gradual increase toward the bark. In our study, the FL was about $2.4 \mathrm{~mm}$ at rings $8-11$, which is somewhat higher than previously reported by Lundqvist et al. (2002): $1 \mathrm{~mm}$ close to pith, 1.8-2.2 at ring 10,2-2.5 at ring 15 , and $2.5-3.5$ at rings above 25 .

Generally, fiber-dimension traits show relatively higher heritabilities than those for growth traits in conifer species (Fries 2012; Hannrup et al. 2004; Hong et al. 2014; Nyakuengama et al. 1997). For example, in Scots pine, Hong et al. (2014) reported that the heritabilities of fiber-dimension traits estimated for one sigle site at tree age 40 were $0.26-0.52$, while the heritabilities of growth traits were $0.24-0.27$. In many other conifers, fiber-dimension traits are also reported to be strongly heritable (Ivkovich et al. 2002; Kibblewhite 1999; Riddell et al. 2005; Zobel and Jett 1995). Our results also showed relatively higher heritabilities for fiber-dimension traits (0.34-0.48) than those reported for growth traits $(\sim 0.2)$ at tree age 21 in Norway spruce (Chen et al. 2014). In radiata pine, the broad-sense heritability estimates for RFW, TFW, FWT, and FC were all more than 0.88 in clonal trials (Riddell et al. 2005), yet narrow-sense estimates varied from 0.1 to 0.97 (Riddell et al. 2005; Zobel and Jett 1995).

Across annual rings, heritability of RFW stabilized from ring 6, which was consistent with a previous report in white spruce (Lenz et al. 2011). However, Lenz et al. (2011) 
reported a heritability estimate of ca. 0.7 for RFW, higher than our estimate in Norway spruce (ca. 0.5). Heritability of TFW was lower than that of RFW and stabilized later than the rest of the fiber-dimension traits. Similarly, in white spruce, Lenz et al. (2010) reported that the heritability of TFW was much lower than that of RFW and still did not stabilize before ring 16. For FWT, Lenz et al. (2011) reported that heritability increased gradually from pith to bark across the first 16 rings. However, in our study, FWT increased initially and stabilized by ring 6 , indicating that early selection may be more feasible in Norway spruce if age-age genetic correlations remain high for the outerwood. Heritability for FC increased slowly from a low value close to the pith to moderate close to the bark, as reported in white spruce (Lenz et al. 2010).

In conifers, heritability of FL typically varies from moderate to high (Rozenberg and Cahalan 1997; Zobel and Jett 1995). In our study, estimated heritability of FL (0.41) using joint-site analysis is moderate, which is higher than the 0.29 reported in a southern Swedish trial (Hannrup et al. 2004). In white spruce, Ivkovich et al. (2002) also supported moderate to high heritability for FL at several sites.

\section{Genotype-by-environment interactions for fiber-dimension traits}

We observed relatively high levels of type-B correlations for all fiber-dimension traits $(>0.7)$ indicating that there is very little $\mathrm{G} \times$ $\mathrm{E}$ interaction between the two sites, which suggests that $\mathrm{G} \times \mathrm{E}$ interaction may be negligible for Norway spruce in southern Sweden for fiber-dimension traits. Hannrup et al. (2004) reported lower type-B correlations for FL, FWT, and MFA using fewer than 200 trees and only two rings (ring 5 and ring 15/23).

\section{Impact of selection for diameter and solid-wood properties on fiber dimensions}

In our study, estimated genetic correlations between diameter and fiber-dimension traits are low to moderate, with the strongest correlations appearing with FWT $(-0.51)$ and RFW (0.49). The fibers of trees selected for higher growth will thus tend to have larger diameters with thinner walls and thus lower wood density $(-0.61)$. Also, FC tends to decrease $(-0.24)$ as stem diameter increases. All these correlations were stable across rings (Table 3). Adverse genetic correlations between stem diameter and fiber-dimension traits have been reported for other conifer species, and the degree of phenotypic and genetic correlation among these traits estimated for the whole increment cores and across annual rings is variable among species (Lenz et al. 2010; Lenz et al. 2011; Zobel and Jett 1995). Adverse genetic correlations observed in this study for Norway spruce accord with those reported for Scots pine (Fries 2012; Hong et al. 2014) and radiata pine (Wu et al. 2008), as well as white spruce (Ivkovich et al. 2002; Park et al. 2012). Especially, high positive correlations were observed between wood density or MOE and FWT, while moderate positive correlations were observed with $\mathrm{FC}$ and moderate and negative correlations with RFW. Nyakuengama et al. (1997) reported that FWT is the main determinant controlling wood density also in radiata pine, which is in line with results found in our study. Similar results have been found in Scots pine (Hong et al. 2014) and white spruce (Lenz et al. 2010). The moderate negative correlation between TFW and density observed in our study also is in agreement with a previous study in Norway spruce (Hannrup et al. 2004). However, Hong et al. (2014) reported a negligible positive genetic correlation between wood density and TFW in Scots pine. Also, Lenz et al. (2010) showed moderate negative and positive genetic correlations between density and RFW and TFW, respectively. The correlations of FL with wood density, MOE, and MFA were low; consequently, selection for diameter or solid-wood properties will have a low impact on the length of the fibers.

Selection indices indicated that simultaneous selection of diameter and MOE had the highest profitability, independently of adding restriction on FL into the model. As expected from the observed genetic correlations, selection based on diameter or MOE affects mainly RFW, FWT, and FC, although those effects are low and range between -0.04 and $7.13 \%$, while for TFW and FL, the changes are negligible. Moreover, when diameter and MOE were considered jointly, the effect on RFW, FWT, and FC decreased substantially, with the only exception being FC under scenario $\mathrm{C}$. The effect on TFW and FL was negligible under all three scenarios. In this respect and considering the typically higher added value of sawn products, the biggest challenge in breeding of Norway spruce is to balance growth and MOE due to the estimated high adverse genetic correlation between these traits observed in the species. In our study, we considered a single scenario for the simultaneous selection of diameter and MOE (10 times weight for MOE); therefore, it is important to highlight that results cannot be extrapolated to all potential scenarios. Instead, a more profitable selection index could be achieved by applying more accurate economic weights based on the current Norway spruce integrated production system for both sawn timber and pulp and paper products.

\section{Potential for early selection}

Age-age correlation from early rings to the reference ring 15 was very high in this study, supporting the idea that early selection for fiber-dimension traits would be highly efficient. Early selection efficiency of RFW stabilized around 1 from ring 6, which is earlier than reported by Lenz et al. (2011) in white spruce. Similarly, our study indicates that FWT 
stabilizes at ring 10, again earlier than reported in white spruce where no stabilization of the trait was observed before reference ring 16 (Lenz et al. 2011).

\section{Conclusions}

1. Heritabilities were moderate to high for all fiberdimension traits.

2. High type-B genetic correlations between sites were found for fiber-dimension traits, indicating that $G \times E$ interactions of these traits are unimportant for Norway spruce breeding in southern Sweden.

3. Genetic correlations observed between stem diameter or solid-wood properties and RFW, FWT, or FC were moderate to high, and the correlations between these traits and the rest of the fiber dimensions were low. A minimum of $90 \%$ of selection efficiency will be achieved by early selection at rings $5,10,8$, and 8 for RFW, TFW, FWT, and $\mathrm{FC}$, respectively.

4. Selection based on stem diameter and MOE (alone or combined) will have moderate or no effects on RFW, FWT, and FC and negligible effects on the rest of the fiber dimensions.

5. Restricting FL change as an addition to the stem diameter and MOE selection index should not materially improve profitability.

6. Early selection is highly effective for Norway spruce from ring 5 for RFW and from rings 8-10 for TFW, FWT, and FC.

Acknowledgments The design of the sampling, measurements, calculation of averages, and organization of the data into the database was performed within the strategic research program Bio4Energy, funded by the Swedish government. The trial data and samples were provided by Skogforsk and managed by Johan Malm and other technical staff with funding from the Swedish Spruce Genome Sequencing project. The comprehensive set of wood and fiber data from pith to bark was produced at Innventia, where the samples were prepared and analyzed using the SilviScan instrument; annual rings located; and averages were calculated by Åke Hansson, Thomas Trost, and other researchers; and Thomas Grahn organized all these data in the Bio4Energy Trait Database, ready for the later steps of the evaluation. FL was measured by Rafal Raczkowski and Stefana Ganea at UPSC. We also acknowledge the Swedish research Council (VR) and the Swedish Governmental Agency for Innovation Systems (VINNOVA). The sites for the two trials were kindly provided by the dioceses of Lund and Linköping. Colin Matheson from CSIRO, Australia, edited the English.

Data Archiving Statement The raw quantitative traits data from SilviScan are currently archived in Innventia AB database, and the accession numbers will be supplied for further use of the data for collaboration.

Open Access This article is distributed under the terms of the Creative Commons Attribution 4.0 International License (http:// creativecommons.org/licenses/by/4.0/), which permits unrestricted use, distribution, and reproduction in any medium, provided you give appropriate credit to the original author(s) and the source, provide a link to the Creative Commons license, and indicate if changes were made.

\section{References}

Baltunis BS, Wu HX, Powell MB (2007) Inheritance of density, microfibril angle, and modulus of elasticity in juvenile wood of Pinus radiata at two locations in Australia. Can J For Res 37:21642174. doi:10.1139/x07-061

Bergqvist G, Bergsten U, Ahlqvist B (1997) Effect of radial increment core diameter on tracheid length measurement in Norway spruce. Wood Sci Technol:241-250

Burdon RD (1977) Genetic correlation as a concept for studying genotype-environment interaction in forest tree breeding. Silvae Genet 26:168-175

Chen Z-Q, García Gil MR, Karlsson B, Lundqvist S-O, Olsson L, Wu HX (2014) Inheritance of growth and solid wood quality traits in a large Norway spruce population tested at two locations in southern Sweden. Tree Genet Genomes 10:1291-1303. doi:10.1007 /s11295-014-0761-x

Chen Z-Q, Abramowicz K, Raczkowski R, Ganea S, Wu HX, Lundqvist S-O, Mörling T, Sjöstedt de Luna S, García Gil MR, Mellerowicz EJ (2016) Method for accurate fiber length determination from increment cores for large-scale population analyses in Norway spruce. Holzforschung 70:829-838. doi:10.1515/hf-2015-0138

Cunningham EP, Moen RA, Gjedrem T (1970) Restriction of selection indexes. Biometrics 26:67-74. doi:10.2307/2529045

Evans R (1994) Rapid measurement of the transverse dimensions of tracheids in radial wood sections from Pinus radiata. Holzforschung 48:168-172. doi:10.1515/hfsg.1994.48.2.168

Evans R (2006) Wood stiffness by X-ray diffractometry. In: Stokke DD, Groom HL (eds) Characterization of the cellulosic cell wall. Wiley, Hoboken, pp. 138-146

Evans R, Downes G, Menz D, Stringer S (1995) Rapid measurement of variation in tracheid transverse dimensions in a radiata pine tree. Appita J 48:134-138

Falconer D, Mackay T (1996) Introduction to quantitative genetics, 4th edn. Longman, New York

Fries A (2012) Genetic parameters, genetic gain and correlated responses in growth, fibre dimensions and wood density in a Scots pine breeding population. Ann For Sci 69:783-794. doi:10.1007/s13595-0120202-7

Gilmour AR, Gogel B, Cullis B, Thompson R (2009) ASReml user guide release 3.0. VSN International Ltd, Hemel Hempstead, UK

Gräns D, Hannrup B, Isik F, Lundqvist S-O, McKeand S (2009) Genetic variation and relationships to growth traits for microfibril angle, wood density and modulus of elasticity in a Picea abies clonal trial in southern Sweden. Scand. J For Res 24:494-503. doi:10.1080 /02827580903280061

Hannrup B, Ekberg I (1998) Age-age correlations for tracheid length and wood density in Pinus sylvestris. Can J For Res 28:1373-1379. doi: $10.1139 / \mathrm{x} 98-124$

Hannrup B, Cahalan C, Chantre G, Grabner M, Karlsson B, Le Bayon I, Jones GL, Muller U, Pereira H, Rodrigues JC, Rosner S, Rozenberg P, Wilhelmsson L, Wimmer R (2004) Genetic parameters of growth and wood quality traits in Picea abies. Scand. J For Res 19:14-29. doi:10.1080/02827580310019536

Hong Z, Fries A, Wu HX (2014) High negative genetic correlations between growth traits and wood properties suggest incorporating multiple traits selection including economic weights for the future Scots pine breeding programs. Ann For Sci 71:463-472. doi:10.1007/s13595-014-0359-3 
Hong Z, Fries A, Wu HX (2015) Age trend of heritability, genetic correlation, and efficiency of early selection for wood quality traits in Scots pine. Can J For Res 45:817-825. doi:10.1139/cjfr-2014-0465

Ivković M, Wu HX, McRae TA, Powell MB (2006) Developing breeding objectives for radiata pine structural wood production. I. Bioeconomic model and economic weights. Can J For Res 36: 2920-2931

Ivkovich M, Namkoong G, Koshy M (2002) Genetic variation in wood properties of interior spruce. II. Tracheid characteristics. Can J For Res 32:2128-2139. doi:10.1139/x02-139

Kibblewhite RP (1999) Designer fibres for improved papers through exploiting genetic variation in wood microstructure. Appita J 52: 429-436

Kumar S, Lee J (2002) Age-age correlations and early selection for endof-rotation wood density in radiata pine. For Genet 9:323-330

Lenz P, Cloutier A, MacKay J, Beaulieu J (2010) Genetic control of wood properties in Picea glauca - an analysis of trends with cambial age. Can J For Res 40:703-715. doi:10.1139/X10-014

Lenz P, MacKay J, Rainville A, Cloutier A, Beaulieu J (2011) The influence of cambial age on breeding for wood properties in Picea glauca. Tree Genet Genomes 7:641-653. doi:10.1007/s11295-0110364-8

Li L, Wu HX (2005) Efficiency of early selection for rotation-aged growth and wood density traits in Pinus radiata. Can J For Res 35:2019-2029. doi:10.1139/x05-134

Lundgren C (2004) Cell wall thickness and tangential and radial cell diameter of fertilized and irrigated Norway spruce. Silva Fennica 38:95-106

Lundqvist S-O, Ekenstedt F, Grahn T, Wilhelmsson L (2002) A system of models for fiber properties in Norway spruce and Scots pine and tools for simulation. In Proceeding, IUFRO S5.01-04 Fourth Workshop. Connection between forest resources and wood quality: modelling approaches and simulation software, Harrison Hot Springs, Canada, 2002. pp 8-15

Lundqvist S-O, Grahn T, Hedenberg Ö (2005) Models for fibre dimensions in different softwood species. Simulation and comparison of within and between tree variations for Norway and Sitka spruce, Scots and Loblolly pine. In: Proceedings IUFRO Conference, Auckland, New Zealand, 2005.

McLean JP, Moore JR, Gardiner BA, Lee SJ, Mochan SJ, Jarvis MC (2016) Variation of radial wood properties from genetically improved Sitka spruce in the UK. Forestry 89:109-116

Mitchell MD, Denne MP (1997) Variation in density of Picea sitchensis in relation to within-tree trends in tracheid diameter and wall thickness. Forestry 70:47-60. doi:10.1093/forestry/70.1.47

Molteberg D, Høibø O (2007) Modelling of wood density and fibre dimensions in mature Norway spruce. Can J For Res 37:1373-1389
Mörling T, Sjöstedt-de Luna S, Svensson I, Fries A, Ericsson T (2003) A method to estimate fibre length distribution in conifers based on wood samples from increment cores. Holzforschung 57(3):248-254

Mrode RA, Thompson R (2005) Linear models for the prediction of animal breeding values. CABI, UK

Nyakuengama GJ, Matheson C, Spencer DJ, Evans R, Vinden P (1997) Time trends in the genetic control of wood microstructure traits in Pinus radiata. Appita J 50:486-494

Park Y-S, Weng Y, Mansfield S (2012) Genetic effects on wood quality traits of plantation-grown white spruce (Picea glauca) and their relationships with growth. Tree Genet Genomes 8:303-311. doi:10.1007/s11295-011-0441-z

Riddell MJC, Kibblewhite RP, Shelbourne CJA (2005) Clonal variation in wood, chemical, and kraft fibre and handsheet properties of slabwood and toplogs in 27-year-old radiata pine. Appita J 58: $149-155$

Rosvall O, Ståhl P, Almqvist C, Anderson B, Berlin M, Ericsson T, Eriksson M, Gregorsson B, Hajek J, Hallander J, Högberg K, Jansson G, Karlsson B, Kroon J, Lindgren D, Mullin T, Stener L. 2011. Review of the Swedish tree breeding programme. Skogforsk Internal Report.

Rozenberg PH, Cahalan CH (1997) Spruce and wood quality: genetic aspects (a review). Silvae Genet:270-279

Scallan AM, Green HV (1974) A technique for determining the transverse dimensions of the fibres in wood. Wood Fiber Sci 5:323-333

Svensson I, Sjöstedt-de Luna S (2010) Asymptotic properties of a stochastic EM algorithm for mixtures with censored data. J Stat Plan Infer 140:111-127. doi:10.1016/j.jspi.2009.06.014

Svensson I, Sjöstedt-de Luna S, Bondesson L (2006) Estimation of wood fibre length distributions from censored data through an EM algorithm. Scand J Stat 33:503-522. doi:10.1111/j.14679469.2006.00501.x

White TL, Adams WT, Neale DB (2007) Forest genetics. CABI, Wallingford

Wimmer R, Downes GM, Evans R, Rasmussen G, French J (2002) Direct effects of wood characteristics on pulp and handsheet properties of Eucalyptus globulus. Holzforschung 56:244-252. doi:10.1515 /hf.2002.040

Wu HX, Powell MB, Yang JL, Ivković M, McRae TA (2007) Efficiency of early selection for rotation-aged wood quality traits in radiata pine. Ann For Sci 64:1-9

Wu HX, Ivković M, Gapare WJ, Matheson AC, Baltunis BS, Powell MB, McRae TA (2008) Breeding for wood quality and profit in radiata pine: a review of genetic parameters. N Z J For Sci 38:56-87

Zobel BJ, Jett JB (1995) Genetics of wood production. Springer, Berlin 